Çukurova Üniversitesi Mühendislik Mimarlık Fakültesi Dergisi, 33(4), ss. 17-30, Aralık 2018

\title{
Çocuk Yoğun Bakım Ünitesinde Çok Kriterli Karar Verme ile Mekanik Ventilatör Seçimi ve Bir Uygulama Örneği
}

\author{
Z. Figen ANTMEN', Pınar Míç ${ }^{* 1}$ \\ ${ }^{1}$ Çukurova Üniversitesi, Mühendislik Fakültesi, Endüstri Mühendisliği Bölümü, Adana
}

Geliş tarihi: 02.07.2018 Kabul tarihi: 25.12.2018

$\ddot{O} z$

Yoğun bakım üniteleri, hayati önem arz eden tıbbi tedavi birimlerinden biridir. Bu ünitede yapılacak en küçük hata veya gecikme, telafisi olmayan sonuçlar doğurabilir. Yoğun bakımlarda başvurulan en önemli cihazlardan birisi, hastaya yapay solunum desteği veren mekanik ventilatörlerdir. Ventilatör seçimleri ve parametre ayarları, hastanın yaşamını devam ettirmesinde en önemli faktörlerdir. Bu nedenle, ventilatör seçiminin en doğru şekilde gerçekleştirilmesi kritik önem arz eder. Bu çalışmada, Adana ilindeki bir hastanenin çocuk yoğun bakım ünitesinde ventilatör seçimi için çok kriterli karar verme tekniklerinden Analitik Hiyerarşi Prosesi (AHP) ve bulanık TOPSIS yöntemleri kullanılmışır. Her iki yöntem neticesinde çıkan sonuçlar karşılaştırılmıştır.

Anahtar Kelimeler: Yoğun bakım ünitesi, Ventilatör, Çok kriterli karar verme, AHP, TOPSIS, Bulanık mantık

\section{Selection of Mechanical Ventilator in Pediatric Intensive Care Unit by Multi- Criteria Decision Making and a Case Study}

\begin{abstract}
Intensive care units are one of the medical treatment units which are of vital importance. The minimum fault or delay in this unit can cause nonrecoverable results. One of the most important tools applied in intensive cares are mechanic ventilators which supports artificial respiration to the patient. Appropriate ventilator selections and ventilatory parameters are the most significant factors for patient's survival. Therefore, carrying out the ventilator selection most correctly is critical. In this study, Analytic Hierarcy Process (AHP) and fuzzy TOPSIS methods which are multi criteria decision making techniques are utilized for selection of ventilator in a child intensive care unit of a hospital in Adana county. The results obtained from both methods are compared.
\end{abstract}

Keywords: Intensive care unit, Ventilator, Multi criteria decision making, AHP, TOPSIS, Fuzzy logic

*Sorumlu yazar (Corresponding author): Pınar Miç,pmic@cu.edu.tr 


\section{GíRiș}

Yoğun bakım ünitesi; hayatı tehdit eden kritik bir hastalık varlığında hastaların yakın takip ve tedavilerinin yapıldığı özel ünitelerdir. Solunum yetmezliği, şiddetli enfeksiyonlar (ağır zatürre, menenjit gibi), kalp krizi, ani gelişen kalp ritmi bozuklukları, koma, şok, ciddi travma ve kazalar, zehirlenmeler ve ameliyat sonrası dönemde yakın izlem gerektiren özel durumlar en sık yoğun bakım ünitesine yatırılma nedenleri olarak sayılabilir.

Yoğun bakım ünitelerinde gerçekleştirilen ventilatör tedavisi, ventilatör cihazı adı verilen alet ile yapilır ve bu prosese "ventilasyon" veya "mekanik ventilasyon" denilmektedir [1]. Bu süreçler, hayatta kalmanın temel gereksinimini devam ettirmek gerekliliğinden ötürü ortaya çıkmıştır. Nitekim yaşamanın esas ihtiyaçlarından biri yeterli miktarda havayı almak ve bu havayı tüm hücrelerimize transfer etmektir [1]. Kalp ve kan hücreleri dağıtımdan sorumlu iken, akciğerlerimiz, atmosfer ve iç organlar arasında uzlaştırıcı bir pozisyon alarak oksijen $\left(\mathrm{O}_{2}\right)$ ve karbondioksit $\left(\mathrm{CO}_{2}\right)$ değiş tokuşunu gerçekleştirir [1]. Oksijenin temini ve karbondioksitin ortadan kaldırılması nefes almanın en önemli iki bileşenidir ve bu proses "nefes alma" olarak adlandırılır. Solunum fonksiyonu, sağlıklı yaşayan insanlarda bağımsız bir şekilde gerçekleştirilirken; akciğer hastalığı ve solunum yetmezliği olanlarda ise soluma işlemi, yapay bir şekilde ve hasta düzelene kadar, istenilen parametreler ile ventilatör cihazları vasıtasıyla gerçekleştirilir.

Mekanik ventilasyon olarak gerçekleştirilen ilk örnek 1541'de Andreas Vesalius tarafindan yapılmıştır. Vesalius, ölmek üzere olan bir köpeğin soluk borusuna kanül yerleştirerek akciğerlerini havalandırmış ve neticede kalp atışlarında düzelme saptamıştır [2]. 20. yy.'da ise 1919 yılında Dr. Philip Drinker, "Drinker Solunum Aygitı" ile literatüre geçmiştir [3]. 1931'de John Haven Emerson'un geliştirdiği çelik akciğer 1948-49 çocuk felci epidemilerinde kullanılmıştır ama bu cihazların çok yer kapladığı, hasta bakımının iyi olmadığı ve dolaşımı etkilediği gibi yan etkileri de saptanmıştır [3].
Mekanik ventilasyon, birçok farklı hasta popülasyonu için hastanelerde özellikle yoğun bakım ve sürekli bakımda en yaygın olarak kullanılan tedavi yöntemlerinden biridir. Ventilatörün kendisinin ve parametrelerinin uygun seçimi ve ventilatörden zamanında ayrılma, böyle bir tedavinin çıtılarını belirlemede ana faktörlerdir. Etkili ve iyi tasarlanmış karar destek sistemleri günümüzdeki gelişmiş mekanik ventilatörlerin çıktı parametrelerini düzenlemede değerli aletler olarak kullanılabilir.

Hastaların mekanik ventilasyonu, üç $\operatorname{ard}$ ş̧1k aşamada gerçekleşir. Bunlar; hastayı makineye bağlama ve ventilasyonu başlatma, altta yatan hastalık için yeterli ventilasyonu idame ettirme ve son olarak normal doğal solunumu tekrar kurmak için mekanik desteğe son vermektir. İkinci ve üçüncü aşamada (sürdürme aşaması ve ventilatörü bırakma aşaması), makine ayarları ve düzeltmeler genellikle arter kan gaz analizine, akciğer ve göğüs duvarı mekaniklerine dayalı rasyonel kararlar ile yönlendirilir. Birinci aşamada, hasta başlangıçta ventilatör makinesine bağlandıysa, hastanın tam olarak ne kadar ventilasyona ihtiyacı olduğunu bilen ilgili uzmanın ventilatör parametrelerini önceden ayarlaması gerekir. Doktorlar ve solunum tedavisi yapanlar genellikle bunu kaba tahminler veya klinik deneyimleri ile yaparlar [4].

Mekanik ventilatör cihazı ile hastaya iki şekilde solunum desteği verilebilir: Non-invazif mekanik ventilasyon ve İnvazif mekanik ventilasyon. Noninvazif mekanik ventilasyon, soluk borusuna (trakea) delik açılmadan maske yardımıyla solunum desteği veren cihazlar sayesinde yapılır. Belirli parametrelerde çalışan bu cihazların amacı solunum problemini gidermek ve vücuttaki oksijen oranını sağlıklı bir seviyeye ulaştırmaktır. Solunumun tamamen durmasına karşı da bu cihazlar tercih edilmektedir. Non-invazif uygulamalarda önemli olan bir diğer unsur uygulama sirasında kullanılan maskelerdir. Hastanın yüz yapısına ve solunum uygulamasına göre maskeler çeşitlilik gösterir. Hangi tip maskenin kullanılacağı ise hekim tarafından belirlenir. Non-invazif mekanik ventilasyon esnasında sıklıkla kullanılan maske çeşitleri şunlardır [5,6]: 
- Burun Yastıkçıklı Maske

- Nasal Kanül

- Nasal Maske

- Ora-Nasal Maske

- Oral Maske

- Tüm Yüz Maske

İnvazif mekanik ventilasyonda ise hastaya trakeostomi kanülü veya endotrakeal tüp takılır. Endotrakeal tüp geçici solunum sıkıntılarında ağızdan uygulanmaktadır. Fakat endotrakeal tüpün ses tellerine zarar verme riski vardır ve bu da hastanın konuşma yetisini kaybetme riskine neden olabilir. Bu nedenlerle eğer hasta 5 günden fazla mekanik ventilatöre bağlı kalacaksa, invazif mekanik ventilasyonda maske kullanımına gerek yoktur. $\mathrm{Bu}$ tip solunumda kullanılan mekanik ventilatör cihazları, non-invazif mekanik ventilatör cihazlarından daha gelişmiş seviyededir $[7,8]$.

Bu işlemleri yaparken; yüksek teknolojik ve pahalı donanım ile karmaşık görüntüleme yöntemlerinin kullanımı ve yorumlanması; aşırı iş gücü gereksinimi; bu yüksek teknolojiyi kullanabilen ve iyi bilimsel birikime sahip devamlı bir yoğun bakım ekibinin 24 saat gerekliliğinin mevcut olduğu gerçeği de göz önünde bulundurulmalıdır [7].

$\mathrm{Bu}$ bilgiler ışı̆̆ında, yanlış yapılan ventilatör seçimleri ve yanlış parametre ayarları geri dönülemez sonuçlar doğuracağından dolayı; hastalara uygulanan mekanik ventilatörlerin doğru bir şekilde seçilmesinin ve parametrelerinin uygun ayarlanmasının hayati önem taşıdığı bir gerçektir. Ventilatör seçerken uygulanan mod, tidal hacim, kullanım kolaylığ vb. gibi kriterler açısından; ventilatör seçimi çok kriterli bir karar verme problemi olarak düşünülebilir. Bu doğrultuda, bu çalışmada, Adana ilindeki bir hastanede, çocuk yoğun bakım ünitesindeki entübe olan invazif mekanik ventilatör seçimi, çok kriterli bir karar verme tekniği olan Analitik Hiyerarşi Prosesi (AHP) ve bulanık Technique for Order Preference by Similarity to Ideal Solution (TOPSIS) yöntemleri ile yapılmış ve sonuçlar karşılaştırılmıştır. Çalışmanın, literatürde bu alandaki boşluğu gidermesi ve gelecekteki çalışmalara dayanak olması beklenmektedir.

\section{2. ÖNCEKİ ÇALIŞMALAR}

Çok Kriterli Karar Verme (ÇKKV) yöntemleri ile mekanik ventilatör seçimi problemi için literatür incelenmiş ama bu konuda yapılmış sadece bir çalışmaya rastlanmıştır. Sloane ve ark. (2003), çalışmalarında, yeni açılan bir kadın sağlığı hastanesinde yeni doğan ventilatör seçimini desteklemek ve belgelemek için çok disiplinli ve disiplinler arası bir süreç olan AHP'yi kullanmışlardır [9]. En iyi ventilatör, en yüksek satın alma fiyatına sahip olmasına rağmen; güvenliği, klinik ve teknik özellikleri ve bunlara ilaveten daha düşük işletme maliyetleri faktörlerinden dolayı yüksek puan almıştır [9].

Literatür, çoğunlukla, sağlık hizmeti ve uygulamalarında ÇKKV ve teknikleri üzerine yoğunlaşmıştır. Mevcut çalışmalarda ele alınan bazı yaklaşımlar şunlardır:

- Sağlık hizmetinde çok kriterli karar analizinin genel bir literatür incelemesi $[10,11]$,

- AHP kullanımının literatür incelemesi [12, $13]$

- Tıbbi veya sağlık hizmeti ile ilgili konularda AHP tekniğinin kullanımı [14-16], VIKOR (ViseKriterijumska Optimizacija I Kompromisno Resenje) tekniğinin kullanımı [17], bulanık-VIKOR tekniğinin kullanımı $[18,19]$, bulanık ANP (Analitik A $\breve{g}$ Prosesi) kullanımı [20], bulanık-TOPSIS (Technique for Order Preference by Similarity to Ideal Solution) kullanımı [21];

- Birden fazla ÇKKV tekniğin birleştirilmesi ile ortaya çıkarılan hibrid yöntemler [22,23];

- Yeni bir ÇKKV yaklaşımı sunma [24];

- Hastane hizmet kalitesi [25], sağlik hizmet sistemi kalitesi [16], hastane performansı 
[26], elektronik hizmet kalitesi [27], sağlık atık teknolojisi değerlendirme [28] yaklaşımları;

- Sağlık hizmeti atık arıtımı teknolojisi seçimi [29].

\section{MATERYAL VE METOT}

\subsection{Materyal}

Çalışma, Adana ili bünyesindeki bir hastanede çocuk yoğun bakım ünitesinde entübe olan (entübasyon tüpü takılan) invazif mekanik ventilatör seçimi için gerçekleştirilmiştir. Doğru ve gerçek verilerle çalışmayı yürütebilmek amacıyla, ilgili kişi olarak belirlenen 4 çocuk yoğun bakım ünitesi doktoru ile görüşülmüş; görüşmeler neticesinde bu kişilerin görüş ve onayları doğrultusunda ventilatör seçimi için 7 alternatif ve ventilatörlerin seçilmesi için 13 kriter belirlenmiştir. İnvazif mekanik ventilatörlerde non-invaziflik özelliğinin olması, ventilatör seçiminde önem arz ettiğinden, çalışmada bu kriter de (bknz K13) kullanılmıştır.

Alternatif ventilatörler şöyle sıralanabilir: Drager (A1), Maque (A2), Sum-1 (A3), Hamilton (A4), GE (A5), Ertunç-Ertan (A6) ve Servo (A7). Ventilatörün seçiminde kullanılmak üzere belirlenen kriterler ise şunlardır:

- Ventilatörün yeni doğana ve çocuğa uygun olma durumu (K1):

- Yeni doğana uygun olması,

- Çocuğa uygun olmasi,

- Tüm yaşlara uygun olmasi.

- Ventilatörün içerdiği modlar (K2):

- En az 3 mod içermesi,

- Çoğu modu içermesi,

- Tüm modları içermesi.

- Ventilatörün bataryası (K3):

- 6 saat,

- 12 saat,

- 24 saat.

- Ventilatörün farklı ölçüm yapabilmesi (K4):

- Standart ölçüm yapması,
- Özellikli ölçüm yapabilme özelliğine sahip olmasi.

- Manevra (K5):

- Ventilatörün özel manevra kabiliyetinin olmas1/olmamas1.

- Ventilatörden ayrilma (K6):

- Ventilatörden ayrilmanın zor olması.

- Ventilatörden ayrılmayı kolaylaştırması,

- Kullanım kolaylığı (K7):

- Kullanımının kolay olması/olmaması.

- Bakım onarım (K8):

- Hizmet hizı,

- Yillik bakım,

- Bakım onarım masrafi.

- Oksijen akış sensörü (K9):

- Oksijen akış sensöründe çok sık değişiklik olmamas1/olmasi.

- Set (K10):

- Set bağımlılığg olmasi/olmaması.

- Yüksek frekanslı osilatör ventilasyon (K11):

- Yüksek frekanslı osilatör ventilasyon özelliğine sahip olmas1/olmamas1.

- Yüksek akışlı oksijen (K12):

- Yüksek akışlı oksijen uygulama özelliği olmas1/olmamas1.

- Non-invaziflik (K13):

- Non-invaziflik özelliği içermesi/ içermemesi.

\subsection{Metot}

Hızla değişen çevresel koşullara uyum sağlamak ve değişime paralel olarak etkin karar alabilmek için karar verme sürecince çok sayıda nitel ve nicel faktöre ihtiyaç vardır. Bu faktörleri bir arada değerlendirebilmek, bilimsel yöntemleri kullanmak ile mümkündür. $\mathrm{Bu}$ süreçte kullanılabilecek yöntemlerin başında ise Çok Kriterli Karar Verme Yöntemleri (ÇKKV) gelmektedir. Bu doğrultuda, bu çalışmada, çocuk yoğun bakım ünitesindeki entübe olan invazif mekanik ventilatör seçimi için etkin ÇKKV yöntemlerinden AHP ve Bulanık TOPSIS yöntemleri kullanılmıştır.

\subsubsection{AHP}

AHP, 1968 yılında Myers ve Alpert ikilisi tarafından ortaya atılmış, $1977^{\prime}$ de ise Thomas L. 
Saaty tarafından; karar verme problemlerinin çözümünde kullanılabilir hale getirilecek şekilde bir model olarak geliştirilmiştir [30]. AHP sürecinin temelde 5 aşaması vardır [31]:

\section{i. Problemin tanımlanması ve kriterlerin hiyerarşik yapısının oluşturulması}

Yöntemin ilk aşaması olan bu safhada, karar verme problemi ve problemin amacı tanımlanır.

\section{ii. İkili karşılaştırmalar yapılması}

$\mathrm{Bu}$ aşamada, karar verecek kişi veya kişiler tarafından, değerlendirilecek kriterlere göre alternatiflerin ikili karşılaştırmaları yapılır. Bu karşılaştırmalarda, Saaty tarafindan geliştirilen Çizelge 1'de verilen ölçek dikkate alınır.

Çizelge 1. İkili karşılaştırmalarda kullanılan önem değerleri ve değer tanımları [31]

\begin{tabular}{|c|l|}
\hline $\begin{array}{c}\text { Önem } \\
\text { Değerleri }\end{array}$ & Değer Tanımları \\
\hline 1 & Eşit önem \\
\hline 3 & Biri diğerine göre zayıf derecede önemli \\
\hline 5 & Kuvvetli ya da esaslı düzeyde önem \\
\hline 7 & $\begin{array}{l}\text { Çok kuvvetli ya da ispatlanmış düzeyde } \\
\text { önem }\end{array}$ \\
\hline 9 & Kesin düzeyde önem \\
\hline $2,4,6,8$ & Ara değerler \\
\hline
\end{tabular}

iii. Kriterler arası karşılaştırma matrisinin olușturulması

$\mathrm{Bu}$ aşamada, kriterler kendi aralarında karşılaştırılır ve Çizelge 2'de verilen karşılaştırma matrisi oluşturulur.

Çizelge 2. Kriterler için ikili karşılaştırma matrisi

\begin{tabular}{|c|c|c|c|c|c|}
\hline & Kriter 1 & Kriter 2 & Kriter 3 &.. & Kriter n \\
\hline Kriter 1 & $a_{1} / a_{1}$ & $a_{1} / a_{2}$ & $a_{1} / a_{3}$ &.. & $a_{1} / a_{n}$ \\
\hline Kriter 2 & $a_{2} / a_{1}$ & $a_{2} / a_{2}$ & $a_{2} / a_{3}$ &.. & $a_{2} / a_{n}$ \\
\hline Kriter 3 & $a_{3} / a_{1}$ & $a / a_{2}$ & $a_{3} / a_{3}$ &.. & $a_{3} / a_{n}$ \\
\hline.. &.. &.. &.. &.. &.. \\
\hline Kriter n & $a_{n} / a_{1}$ & $a_{n} / a_{2}$ & $a_{n} / a_{3}$ &.. & $a_{n} / a_{n}$ \\
\hline
\end{tabular}

$\mathrm{Bu}$ matriste, kriterlerin birbirlerine göre önem seviyeleri belirli bir mantık içerisinde gösterilmektedir.

\section{iv. Kriterlerin önem dağılımlarının belirlenmesi}

Kriterlerin önem dağılımlarını, bir diğer deyişle bütün içerisindeki ağırlıklarını belirlemek için her kriter için sütun vektörü oluşturulur. Bu vektörlerin hesaplanmasında Eşitlik 1'den faydalanılır [31]:

$\mathrm{b}_{\mathrm{ij}}=\frac{\mathrm{a}_{\mathrm{ij}}}{\sum_{\mathrm{i}=1}^{\mathrm{n}} \mathrm{a}_{\mathrm{ij}}}$

Bu formülde, $i$ satırı, $j$ sütunu, $n$ ise kriter sayısını ifade etmektedir. Tüm $n$ kriter için sütun vektörleri matris formatında bir araya getirilerek ayrı bir $C$ matrisi oluşturulur ve bu matris vasıtasıyla kriterlerin birbirlerine göre önem değerlerini gösteren önem dağılımları elde edilir. Bu amaçla, $C$ matrisini oluşturan satır bileşenlerinin aritmetik ortalaması alınır ve $W$ öncelik vektörü Eşitlik 2 ile elde edilir:

$\mathrm{W}_{\mathrm{i}}=\frac{\sum_{\mathrm{i}=1}^{\mathrm{n}} \mathrm{c}_{\mathrm{ij}}}{\mathrm{n}}$

v. Tutarlılık oranının hesaplanması ve sentez

Karar vericilerin kriterler arasında kıyaslama yaparken tutarlı davranıp davranmadığını ölçmek için Tutarlılık Oranı hesaplanır. Bu hesaplamanın özü, kriter sayısı $(n)$ ile Temel Değer $(\lambda)$ adı verilen katsayının karşılaştırılmasına dayanmaktadır. $\quad \lambda$ 'nın hesaplanması için, Çizelge 2'deki karşılaştırma matrisi ile $W$ öncelik vektörünün matris çarpımından $D$ sütun vektörü elde edilir. Eşitlik 3 'te verildiği üzere, bulunan $D$ sütun vektörü ile $\mathrm{W}$ sütun vektörünün karşıl1klı elemanlarının bölümünden her bir kritere ait temel değer elde edilir.

$E_{i}=\frac{d_{i}}{w_{i}}$

$\mathrm{Bu} \quad E_{i}$ değerlerinin ortalaması Eşitlik 4 karşılaştırmaya ait temel değer olan $\lambda^{\prime}$ 'y vermektedir.

$\lambda=\frac{\sum_{\mathrm{i}=1}^{\mathrm{n}} \mathrm{E}_{\mathrm{i}}}{\mathrm{n}}$

$\lambda$ hesabından sonra, Eşitlik 5 ile Tutarlılık Göstergesi $(C I)$ hesaplanır. 
$\mathrm{CI}=\frac{\lambda-\mathrm{n}}{\mathrm{n}-1}$

Son olarak, CI, kriter sayısına göre, Çizelge 3'de verilen Rassallı Göstergesi (RI) değerine bölünerek Tutarlılık oranı elde edilir.

Çizelge 3. Kriter sayısına göre $R I$ değerleri [31]

\begin{tabular}{|c|c|c|c|c|c|c|c|c|c|}
\hline $\mathrm{n}$ & 1 & 2 & 3 & 4 & 5 & 6 &.. & 12 & 13 \\
\hline $\mathrm{RI}$ & 0 & 0 & 0,58 & 0,90 & 1,12 & 1,24 &.. & 1,53 & 1,56 \\
\hline
\end{tabular}

Hesaplanan $C R$ değerinin 0,1 'den küçük olması, karar vericinin yaptığı karşılaştırmaların tutarlı olduğunu gösterecektir [31]. Aksi durumda karar matrisi yeniden düzenlenmelidir.

\subsubsection{Bulanık TOPSIS}

1981 yılında Hwang ve Yoon tarafindan önerilen TOPSIS yöntemi [33] ÇKKV problemlerinde en çok kullanılan yöntemlerden birisidir. Günümüzde problemler ve yargılar genellikle belirsizlik içerdiğinden dolayı; karmaşık ya da iyi tanımlanmamış durumların çözümünde başvurulan bir yöntem olan TOPSIS'te, bu karmaşık durumların dilsel ifadelerle belirtilmesinde bulanık sayılardan yararlanılmaya başlanmıştır [34]. Bu çalışmada da, ventilatör seçimi konusunda daha tutarlı sonuçlara ulaşmak için konu bulanık mantık çerçevesinde ele alınmıştır. Kavramların kesin sınırlamaları olmaksızın sınıflandırıldığı ve 1965 yılında Zadeh tarafından geliştirilen bulanık mantıkta üyelik dereceleri kullanılmaktadır [34]. Çalışmada ventilatör seçimi için kullanılan üyelik fonksiyonu, üçgen bulanık sayılardır. Üçgen üyelik fonksiyonu; bulanık sayının alt sınır değerini gösteren $l$, orta değerini gösteren $m$ ve üst sınırını gösteren $u$ parametreleri ile tanımlanır ve $\mu_{\tilde{\mathrm{n}}}(\mathrm{x})$ üyelik fonksiyonu Eşitlik 6 ile ifade edilir [35]:

$\mu_{\tilde{n}}(x)=\left\{\begin{array}{cc}0 & \\ \frac{x-1}{m-1} & x<1 \\ \frac{x-u}{m-u} & m \leq x \leq m \\ 0 & x>u\end{array}\right.$

Çalışmamızın konusunu oluşturan ventilatör seçiminde Chen (2000) [35] tarafından geliştirilen bulanık TOPSIS yöntemi kullanılmıştır. Aşağıda bu yöntemin aşamaları verilmiştir [35].

\section{i) Karar vericilerin alternatifleri değerlendirmesi}

Başlangıç olarak, $m$ adet alternatifi (ventilatör) değerlendirecek karar vericiler (çocuk yoğun bakım ünitesi doktorları) ve alternatifleri değerlendirirken kullanılacak kriterler belirlenir. Alternatiflerin kümesi $A_{i}=\{1,2, \ldots, m\}$, karar vericilerin kümesi $\mathrm{K}=\{1,2, . ., \mathrm{S}\}$ ve kriterlerin kümesi $C_{j}=\{1,2, . ., n\}$ ile gösterilir.

$\mathrm{Bu}$ işlemi takiben, alternatiflerin ve kriterlerin değerlendirilmesinde kullanılacak uygun dilsel değişkenler belirlenir ve karar vericiler bu dilsel değişkenler yardımıyla alternatifleri ve kriterleri değerlendirir. $\mathrm{Bu}$ değerlendirmeler ve bunlara karşılık gelen bulanık sayılar Çizelge 4 ve Çizelge 5'de gösterilmiştir [36].

Çizelge 4. Karar kriterlerinin ağırlıklarının belirlenmesi için dilsel değişkenler ve üçgen bulanık sayı karşılıkları [36]

\begin{tabular}{|l|l|}
\hline Çok Yüksek (ÇY) & $(0,8,1,1)$ \\
\hline Yüksek (Y) & $(0,7,0,8,0,9)$ \\
\hline Biraz Yüksek (BY) & $(0,5,0,65,0,8)$ \\
\hline Orta (O) & $(0,4,0,5,0,6)$ \\
\hline Biraz Düşük (BD) & $(0,2,0,35,0,5)$ \\
\hline Düşük (D) & $(0,1,0,2,0,3)$ \\
\hline Çok Düşük (ÇD) & $(0,0,0,2)$ \\
\hline
\end{tabular}

Çizelge 5. Alternatiflerin değerlendirilmesi için dilsel değişkenler ve üçgen bulanık sayı karşılıkları [36]

\begin{tabular}{|l|l|}
\hline Çok İyi (Çİ) & $(8,10,10)$ \\
\hline İyi (İ) & $(7,8,9)$ \\
\hline Biraz İyi (Bİ) & $(5,6,5,8)$ \\
\hline Orta (O) & $(4,5,6)$ \\
\hline Biraz Kötü (BK) & $(2,3,5,5)$ \\
\hline Kötü (K) & $(1,2,3)$ \\
\hline Çok Kötü (ÇK) & $(0,0,2)$ \\
\hline
\end{tabular}




\section{ii) Kriterlerin önem ağırlıkları ve alternatiflerin kriter değerlerinin hesaplanması}

$W$ ağırlık vektörü, problem için $n$ seçim kriterinin göreceli önemini belirtir. $\tilde{x}_{i j}$ ise karar vericinin değerlendirdiği $i$ alternatifi için $j$ kriterinin değerini göstermektedir. $j$. kriterin önemi $\widetilde{W}_{j}$ ve her alternatifin değerlendirmesi $\tilde{x}_{i j}$, sırasıyla aşağıdaki Eşitlik 7 ve Eşitlik 8 ile hesaplanır:

$$
\begin{aligned}
& \widetilde{\mathrm{W}}_{\mathrm{j}}=\frac{1}{\mathrm{~s}}\left[\widetilde{\mathrm{W}}_{\mathrm{j}}^{1}+\widetilde{\mathrm{W}}_{\mathrm{j}}^{2}+\ldots+\widetilde{\mathrm{W}}_{\mathrm{j}}^{\mathrm{d}}\right] \\
& \tilde{\mathrm{x}}_{\mathrm{ij}}=\frac{1}{\mathrm{~s}}\left[\tilde{\mathrm{x}}_{\mathrm{ij}}^{1}+\tilde{\mathrm{x}}_{\mathrm{ij}}^{2}+\ldots+\widetilde{\mathrm{x}}_{\mathrm{ij}}^{\mathrm{d}}\right]
\end{aligned}
$$

\section{iii) Bulanık çok kriterli karar verme problemi matrisi oluşturulması}

$\tilde{x}_{i j}$ dilsel ifadesi üçgen bulanık sayılarla $\left(\mathrm{a}_{\mathrm{ij}}\right.$, $\left.\mathrm{b}_{\mathrm{ij}}, \mathrm{c}_{\mathrm{ij}}\right)$ şeklinde; $\widetilde{W}_{j}$ dilsel ifadesi ise $\left(\widetilde{\mathrm{w}}_{1}, \widetilde{\mathrm{w}}_{2}, \widetilde{\mathrm{w}}_{3}\right)$ şeklinde tanımlanır ve bulanık çok kriterli karar verme problemi matrisi $(\widetilde{D})$ oluşturulur:

$\widetilde{\mathrm{D}}=\left[\begin{array}{cccc}\tilde{\mathrm{X}}_{11} & \tilde{\mathrm{X}}_{12} & \ldots & \tilde{\mathrm{X}}_{1 \mathrm{n}} \\ \tilde{\mathrm{X}}_{21} & \tilde{\mathrm{X}}_{22} & \ldots & \tilde{\mathrm{X}}_{2 \mathrm{n}} \\ \vdots & \vdots & \ldots & \vdots \\ \tilde{\mathrm{x}}_{\mathrm{m} 1} & \tilde{\mathrm{x}}_{\mathrm{m} 2} & \ldots & \tilde{\mathrm{x}}_{\mathrm{mn}}\end{array}\right]$

iv) Bulanık karar matrisinin normalize edilmesi

$B$ fayda, $C$ maliyet kriteri olmak üzere $\tilde{R}$ normalize bulanık karar matrisinin elemanları $\tilde{r}_{i j}$; Eşitlik 10 ve Eşitlik 11 ile ifade edilir:

$$
\begin{aligned}
& \tilde{r}_{i j}=\left(\frac{a_{j}}{c_{j}^{*}}, \frac{b_{j}}{c_{j}^{*}}, \frac{c_{j}}{c_{j}^{*}}\right) \quad \mathrm{j} \in \mathrm{B} \text { ve } c_{j}^{*}=\max _{\mathrm{i}} c_{j} \\
& \tilde{r}_{i j}=\left(\frac{a_{j}^{-}}{c_{j}}, \frac{a_{j}^{-}}{c_{j}}, \frac{a_{j}^{-}}{c_{j}}\right) \quad \mathrm{j} \in \mathrm{C} \text { ve } \mathrm{a}_{\mathrm{j}}^{-}=\min _{\mathrm{i}} a_{j}
\end{aligned}
$$

Normalize bulanık karar matrisi $\tilde{R},\left[\tilde{\mathrm{r}}_{\mathrm{ij}}\right]_{\mathrm{mxn}}$ ile gösterilir. Çalışmamızda, amacımız en uygun ventilatörü seçmek ve bu da bir fayda kriteri olduğu için Eşitlik 10 kullanılmıştır.

\section{v) Ağırlıklı normalize edilmiş bulanık karar matrisinin olușturulması}

$\mathrm{Bu}$ adımında, normalize bulanık karar matrisindeki her $\tilde{r}_{i j}$ kriteri, 2. aşamada hesaplanan ağırlıkları olan $\widetilde{W}_{j}$ ile çarpılır. $\tilde{V}$, ağırlıklı normalize edilmiş bulanık karar matrisi olmak üzere, bu işlem, Eşitlik 12 ve Eşitlik 13 ile gösterilir:

$\widetilde{\mathrm{V}}=\left[\tilde{\mathrm{v}}_{\mathrm{ij}}\right]_{\mathrm{mxn}} i=1,2, . ., m ; j=1,2, . ., n$

$\tilde{\mathrm{V}}_{\mathrm{ij}}=\tilde{\mathrm{r}}_{\mathrm{ij}} \mathrm{X} \quad \widetilde{\mathrm{w}}_{\mathrm{j}}$

\section{vi) Bulanık pozitif ideal çözüm ve bulanık negatif ideal çözümden uzaklıkların belirlenmesi}

$\mathrm{Bu}$ aşamada, bulanık pozitif ideal çözüm (FPIS, $\left.A^{*}\right)$ ve bulanık negatif ideal çözüm (FNIS, $A^{-}$) aşağıdaki şekilde tanımlanır:

$A^{*}=\left(\tilde{v}_{1}{ }^{*}, \tilde{v}_{2}{ }^{*}, \ldots, \tilde{v}_{n}{ }^{*}\right)$

$A^{-}=\left(\tilde{v}_{1}^{-}, \tilde{v}_{2}^{-}, \ldots, \tilde{v}_{n}^{-}\right)$

$j=1,2, . ., n$ olmak üzere; $\tilde{\mathrm{v}}_{\mathrm{j}}{ }^{*}=(1,1,1)$ ve $\tilde{\mathrm{v}}_{\mathrm{j}}^{-}=(0,0,0)$ olarak dikkate alınır.

Her alternatifin $A^{*}$ ve $A^{-}$den uzaklıkları olan $d_{i}{ }^{*}$ ve $d_{i}{ }^{-}$sırasıyla Eşitlik 16 ve Eşitlik 17 ile hesaplanır:

$$
\begin{aligned}
& \mathrm{d}_{\mathrm{i}}^{*}=\sum_{\mathrm{j}=1}^{\mathrm{n}} \mathrm{d}_{\mathrm{v}}\left(\tilde{\mathrm{v}}_{\mathrm{j}}, \tilde{\mathrm{v}}_{\mathrm{j}}^{*}\right)= \\
& \sum_{\mathrm{j}=1}^{\mathrm{n}} \sqrt{\frac{1}{3}\left[\left(\mathrm{a}_{\mathrm{ij}}-\mathrm{a}_{\mathrm{i}}^{+}\right)^{2}+\left(\mathrm{b}_{\mathrm{ij}}-\mathrm{b}_{\mathrm{i}}^{+}\right)^{2}+\left(\mathrm{c}_{\mathrm{ij}}-\mathrm{c}_{\mathrm{i}}^{+}\right)^{2}\right]} \quad i= \\
& 1,2, \ldots, m \\
& \mathrm{~d}_{\mathrm{i}}{ }^{-}=\sum_{\mathrm{j}=1}^{\mathrm{n}} \mathrm{d}_{\mathrm{v}}\left(\tilde{\mathrm{v}}_{\mathrm{j}}, \tilde{\mathrm{v}}_{\mathrm{j}}{ }^{-}\right)=
\end{aligned}
$$

$\sum_{\mathrm{j}=1}^{\mathrm{n}} \sqrt{\frac{1}{3}\left[\left(\mathrm{a}_{\mathrm{ij}}-\mathrm{a}_{\mathrm{i}}^{-}\right)^{2}+\left(\mathrm{b}_{\mathrm{ij}}-\mathrm{b}_{\mathrm{i}}^{-}\right)^{2}+\left(\mathrm{c}_{\mathrm{ij}}-\mathrm{c}_{\mathrm{i}}^{-}\right)^{2}\right]} \quad i=$ $1,2, \ldots, m$ 
vii) Yakınlık katsayılarının hesaplanması ve alternatiflerin sıralanması

Son adımda, her bir alternatif için yakınlık katsayısı $\mathrm{C}_{i}$ hesaplanır. $i=1,2, \ldots, m$ olacak şekilde,

$\mathrm{C}_{\mathrm{i}}=\frac{\mathrm{d}_{\mathrm{i}}{ }^{-}}{\mathrm{d}_{\mathrm{i}}{ }^{*}+\mathrm{d}_{\mathrm{i}}{ }^{-}}$

ile formüle edilmiştir. $C_{i}$ değeri 1'e en yakın olan alternatif en iyi alternatif olacak şekilde alternatifler sıralanır.

\section{UYGULAMA VE İKİ YÖNTEMIN KARŞILAŞTIRILMASI}

Çalışmada, AHP ve Bulanık TOPSIS yöntemleri uygulanmış olup takip eden alt bölümlerde de sırasıyla AHP ve Bulanık TOPSIS yöntemleri uygulama sonuçları verilmiştir. Son kısımda bu iki uygulama karşılaştırılmıştır.

\subsection{AHP Yöntemi ve Sonuç}

Uygulamanın AHP basamağı, bu alanda kullanılan bir yazılım olan Super Decisions Yazılımı Versiyon 2.8 ile çözülmüştür. Kriterler ve alt kriterlerin belirlenmesinden sonra, Super Decisions 2.8 yazılımı vasitasıyla kriterler arası bağlantılar yapılmıştır.

Daha sonra, ikili karşılaştırma matrisleri oluşturulmuş ve Çizelge 1'de belirtilen ölçek desteği ile gerekli karşılaştırmalar yapılmıştır. Yapılan bu karşılaştırma değerlendirmeleri Super Decisions 2.8 yazılımına girilmiş, tüm ikili karşılaştırma matrislerinin tutarlılık analizleri yapılarak tutarlılık oranları (CR) hesaplanmıştır. Tüm ikili karşılaştırma matrislerinin CR değerlerinin 0,10'dan küçük olması sağlanarak kriterler arası karşılaştırmaların tutarlı şekilde yapıldığ 1 kontrol edilmiştir. Son olarak, yazılım vasitasıyla bunlar sentez edilerek en iyi ventilatör alternatifi elde edilmiştir. Yazılımın bulduğu sonuç ekranı Şekil 1'de gösterilmektedir. Alternatifler, Ideals değerleri büyükten küçüğe doğru sıralanır ve Ideals değeri en yüksek olan alternatif en iyi sonuç olacaktır.

\begin{tabular}{|c|c|c|c|c|}
\hline \multicolumn{1}{|c|}{ Name } & \multirow{2}{*}{ Graphic } & Ideals & Normals & Raw \\
\hline \hline DRAGER & & 1.000000 & 0.372904 & 0.346268 \\
\hline ERTUNÇ ERTAN & & 0.773402 & 0.288404 & 0.267804 \\
\hline \hline GE & & 0.100837 & 0.037602 & 0.034917 \\
\hline \hline HAMILTON & & 0.365028 & 0.136120 & 0.126397 \\
\hline \hline MAQUE & & 0.156344 & 0.058301 & 0.054137 \\
\hline \hline SERVO & & 0.061787 & 0.023041 & 0.021395 \\
\hline \hline SUM-1 & & 0.224260 & 0.083627 & 0.077654 \\
\hline
\end{tabular}

Şekil 1. Ventilatör seçimi Super Decisions sonuç görüntüsü

\subsection{Bulanık TOPSIS Yöntemi ve Sonuç}

Bulanık TOPSIS yöntemi için, çalışmada kullanılacak kriterler (bknz Bölüm 3.1) belirlendikten sonra, karar vericiler Çizelge 4'deki dilsel ifadeler yardımıyla karar kriterlerini değerlendirmişlerdir ve bu değerlendirmeler Çizelge 6'da verilmiştir. Karar vericilerin kriter değerlendirmeleri Eşitlik 7 ile tek bir değere indirgenmiş ve bu değerler de Çizelge 7'de verilmiştir.

Çizelge 6. Kriter ağırlıklarının karar vericiler tarafindan belirlenmesi

\begin{tabular}{|c|c|c|c|c|}
\hline \multirow{2}{*}{ Kriterler } & \multicolumn{4}{|c|}{ Karar Vericiler } \\
\cline { 2 - 5 } & KV1 & KV2 & KV3 & KV4 \\
\hline K1 & ÇY & Y & Y & ÇY \\
\hline K2 & Y & Y & BY & BY \\
\hline K3 & O & Y & ÇY & O \\
\hline K5 & Y & Y & ÇY & O \\
\hline K6 & ÇD & O & BD & D \\
\hline K7 & Y & BY & OD & ÇD \\
\hline K8 & D & Y & O & BD \\
\hline K9 & BD & O & Y & Y \\
\hline K10 & O & D & BD & D \\
\hline K11 & BD & Y & O & O \\
\hline K12 & O & BD & D & O \\
\hline K13 & D & O & BD & O \\
\hline
\end{tabular}


Çizelge 7. Kriter ağırlıklarının üçgen bulanık sayılarla gösterilmesi

\begin{tabular}{|c|c|}
\hline Kriterler & A ğIrlıklar \\
\hline K1 & $(0,75,0,90,0,95)$ \\
\hline K2 & $(0,60,0,73,0,85)$ \\
\hline K3 & $(0,58,0,70,0,78)$ \\
\hline K4 & $(0,65,0,78,0,85)$ \\
\hline K5 & $(0,23,0,35,0,48)$ \\
\hline K6 & $(0,08,0,14,0,30)$ \\
\hline K8 & $(0,50,0,61,0,73)$ \\
\hline K9 & $(0,35,0,46,0,58)$ \\
\hline K10 & $(0,50,0,61,0,68)$ \\
\hline K11 & $(0,20,0,31,0,43)$ \\
\hline K12 & $(0,43,0,54,0,65)$ \\
\hline K13 & $(0,28,0,39,0,50)$ \\
\hline
\end{tabular}

Sonraki adımda, karar vericiler her bir alternatifi her bir kritere göre Çizelge 5'deki dilsel ifadeler aracılığıyla değerlendirmiştir, bu değerlendirmeler Çizelge 8'de verilmiştir. $\mathrm{Bu}$ değerlendirmeler,
Eşitlik 8 ile tek bir değere indirgenmiş ve bulanık karar matrisi oluşturulmuştur. Çizelge 9, bulanık karar matrisini göstermektedir. Bulanık karar matrisi, Eşitlik 10'da normalize edilmiş bulanık karar matrisine dönüştürülerek bu matris Çizelge 10 ile verilmiştir.

Normalize edilmiş bulanık karar matrisindeki değerlerin her biri, Çizelge 7'de verilen ilgili kriterin ağırlığ gösterilen ağırlıklı normalize edilmiş bulanık karar matrisi elde edilir. Son olarak her bir alternatifin bulanık pozitif ideal çözümden (FPIS) ve bulanık negatif ideal çözümden (FNIS) uzaklıkları Eşitlik 16 ve Eşitlik 17 ile hesaplanır. Uzaklıkların belirlenmesinden sonra, Eşitlik 18 ile her bir alternatifin yakınlık katsayısı hesaplanır. Her alternatif için $d_{i}{ }^{*}, \quad d_{i}{ }^{-}$ve $C_{i}$ değerleri Çizelge 12 'de verilmiştir.

Çizelge 8. Alternatif ventilatörlerin karar vericiler tarafından değerlendirilmesi

\begin{tabular}{|c|c|c|c|c|c|c|c|c|c|c|c|}
\hline \multirow{2}{*}{ Kriterler } & \multirow{2}{*}{ Alternatifler } & \multicolumn{4}{|c|}{ Karar Vericiler } & \multirow{2}{*}{ Kriterler } & \multirow{2}{*}{ Alternatifler } & \multicolumn{4}{|c|}{ Karar Vericiler } \\
\hline & & KV1 & KV2 & KV3 & KV4 & & & KV1 & KV2 & KV3 & KV4 \\
\hline \multirow{7}{*}{ K1 } & A1 & Çİ & $\dot{\mathrm{I}}$ & Çİ & $\dot{\mathrm{I}}$ & \multirow{7}{*}{ K8 } & $\mathrm{A} 1$ & $\dot{\mathrm{I}}$ & $\mathrm{BI}$ & $\dot{\mathrm{I}}$ & $\dot{\mathrm{I}}$ \\
\hline & A2 & Çİ & $\dot{\mathrm{I}}$ & Bİ & Bİ & & A2 & $\mathrm{BI}$ & $\mathrm{O}$ & $\mathrm{BI}$ & $\mathrm{O}$ \\
\hline & A3 & $\dot{\mathrm{I}}$ & Bİ & Çİ & $\mathrm{O}$ & & $\mathrm{A} 3$ & $\mathrm{O}$ & Bİ & $\mathrm{O}$ & Bİ \\
\hline & A4 & $\dot{\mathrm{I}}$ & Bİ & $\mathrm{O}$ & Bİ & & A4 & $\mathrm{BI}$ & $\dot{\mathrm{I}}$ & Bİ & $\dot{\mathrm{I}}$ \\
\hline & A5 & Çİ & Bİ & $\dot{\mathrm{I}}$ & $\mathrm{O}$ & & A5 & $\mathrm{O}$ & BK & $\mathrm{O}$ & $\mathrm{O}$ \\
\hline & A6 & Çİ & $\dot{\mathrm{I}}$ & $\dot{\mathrm{I}}$ & Ç் & & A6 & $\mathrm{O}$ & Bİ & $\mathrm{O}$ & BI \\
\hline & A7 & $\dot{\mathrm{I}}$ & BI & $\mathrm{O}$ & Çİ & & A7 & $\mathrm{O}$ & Bİ & BK & $\mathrm{O}$ \\
\hline \multirow{7}{*}{ K2 } & A1 & $\dot{\mathrm{I}}$ & Çİ & $\dot{\mathrm{I}}$ & Bİ & \multirow{7}{*}{ K9 } & A1 & Bİ & Bİ & $\dot{\mathrm{I}}$ & Çİ \\
\hline & $\mathrm{A} 2$ & BI & $\mathrm{O}$ & $\mathrm{O}$ & BI & & $\mathrm{A} 2$ & $\mathrm{BI}$ & $\mathrm{O}$ & $\mathrm{O}$ & $\mathrm{O}$ \\
\hline & A3 & BI & $\dot{\mathrm{I}}$ & $\dot{\mathrm{I}}$ & $\mathrm{O}$ & & A3 & $\dot{\mathrm{I}}$ & BK & $\mathrm{O}$ & $\mathrm{O}$ \\
\hline & A4 & Bं & $\mathrm{O}$ & $\mathrm{O}$ & $\dot{\mathrm{I}}$ & & A4 & Bİ & $\mathrm{BI}$ & $\mathrm{BI}$ & BI \\
\hline & A5 & $\mathrm{O}$ & $\mathrm{O}$ & Bİ & BI & & A5 & $\mathrm{O}$ & $\mathrm{O}$ & BK & $\dot{\mathrm{I}}$ \\
\hline & A6 & $\mathrm{BI}$ & $\mathrm{BI}$ & Bİ & Bİ & & A6 & Bİ & $\dot{\mathrm{I}}$ & $\mathrm{BI}$ & $\mathrm{O}$ \\
\hline & A7 & $\mathrm{O}$ & Bİ & Bİ & Bİ & & A7 & $\mathrm{O}$ & $\mathrm{O}$ & BK & $\mathrm{O}$ \\
\hline \multirow{7}{*}{ K3 } & $\mathrm{A} 1$ & $\dot{\mathrm{I}}$ & $\dot{\mathrm{I}}$ & $\dot{\mathrm{I}}$ & $\mathrm{O}$ & \multirow{7}{*}{ K10 } & A1 & $\dot{\mathrm{I}}$ & Çİ & Bİ & $\dot{\mathrm{I}}$ \\
\hline & A2 & $\dot{I}$ & $\dot{I}$ & $\mathrm{O}$ & $\mathrm{O}$ & & A2 & $\mathrm{O}$ & $\mathrm{O}$ & BK & BK \\
\hline & $\mathrm{A} 3$ & $\mathrm{O}$ & $\mathrm{O}$ & $\dot{I}$ & Bİ & & $\mathrm{A} 3$ & $\mathrm{BI}$ & $\mathrm{O}$ & $\mathrm{O}$ & $\mathrm{O}$ \\
\hline & A4 & $\mathrm{BI}$ & $\dot{\mathrm{I}}$ & $\dot{\mathrm{I}}$ & Bİ & & A4 & $\dot{\mathrm{I}}$ & BK & BK & $\dot{\mathrm{I}}$ \\
\hline & A5 & BI & $\mathrm{O}$ & $\dot{I}$ & $\mathrm{O}$ & & A5 & BK & ÇK & BK & $\mathrm{O}$ \\
\hline & A6 & $\dot{\mathrm{I}}$ & BI & $\dot{\mathrm{I}}$ & $\dot{\mathrm{I}}$ & & A6 & $\mathrm{O}$ & $\dot{\mathrm{I}}$ & $\mathrm{O}$ & $\mathrm{O}$ \\
\hline & A7 & $\mathrm{O}$ & $\dot{\mathrm{I}}$ & Bİ & $\dot{I}$ & & A7 & $\mathrm{K}$ & $\mathrm{O}$ & BI & $\mathrm{O}$ \\
\hline \multirow{7}{*}{ K4 } & A1 & $\dot{\mathrm{I}}$ & $\dot{\mathrm{I}}$ & BI & Ç் & \multirow{7}{*}{ K11 } & A1 & BI & $\dot{\mathrm{I}}$ & Ç் & BI \\
\hline & A2 & $\dot{\mathrm{I}}$ & BI & $\mathrm{BI}$ & $\mathrm{O}$ & & A2 & $\dot{\mathrm{I}}$ & $\mathrm{BI}$ & BI & BI \\
\hline & A3 & $\dot{\mathrm{I}}$ & $\dot{\mathrm{I}}$ & $\mathrm{O}$ & $\mathrm{O}$ & & A3 & $\mathrm{O}$ & $\mathrm{O}$ & BK & BI \\
\hline & A4 & $\mathrm{O}$ & BI & $\mathrm{BI}$ & BI & & A4 & $\mathrm{O}$ & $\dot{\mathrm{I}}$ & $\mathrm{O}$ & $\mathrm{O}$ \\
\hline & A5 & Bİ & Bİ & $\mathrm{O}$ & $\mathrm{O}$ & & A5 & BK & $\mathrm{O}$ & $\mathrm{O}$ & $\dot{\mathrm{I}}$ \\
\hline & A6 & Çİ & $\dot{\mathrm{I}}$ & $\dot{\mathrm{I}}$ & $\mathrm{O}$ & & A6 & $\mathrm{O}$ & $\dot{\mathrm{I}}$ & $\mathrm{O}$ & $\dot{\mathrm{I}}$ \\
\hline & A7 & $\mathrm{O}$ & $\mathrm{O}$ & $\mathrm{O}$ & $\mathrm{O}$ & & A7 & $\mathrm{O}$ & $\mathrm{O}$ & $\mathrm{O}$ & $\mathrm{O}$ \\
\hline
\end{tabular}


Cizelge 8 (Devam)

\begin{tabular}{|c|c|c|c|c|c|c|c|c|c|c|c|}
\hline \multirow{2}{*}{ Kriterler } & \multirow{2}{*}{ Alternatifler } & \multicolumn{4}{|c|}{ Karar Vericiler } & \multirow{2}{*}{ Kriterler } & \multirow{2}{*}{ Alternatifler } & \multicolumn{4}{|c|}{ Karar Vericiler } \\
\hline & & KV1 & KV2 & KV3 & KV4 & & & KV1 & KV2 & KV3 & KV4 \\
\hline \multirow{7}{*}{ K5 } & A1 & Bİ & Ç̇ & $\dot{\mathrm{I}}$ & $\dot{\mathrm{I}}$ & \multirow{7}{*}{ K12 } & A1 & Bİ & $\mathrm{O}$ & Cì & $\dot{\mathrm{I}}$ \\
\hline & A2 & $\dot{\mathrm{I}}$ & $\mathrm{O}$ & $\mathrm{O}$ & $\mathrm{O}$ & & A2 & $\mathrm{BK}$ & $\mathrm{BK}$ & $\mathrm{BK}$ & BK \\
\hline & A3 & BÍ & $\dot{\mathrm{I}}$ & $\mathrm{O}$ & $\dot{\mathrm{I}}$ & & $\mathrm{A} 3$ & $\dot{\mathrm{I}}$ & $\mathrm{O}$ & $\mathrm{O}$ & $\dot{\mathrm{I}}$ \\
\hline & $\mathrm{A} 4$ & $\mathrm{~K}$ & $\mathrm{O}$ & $\mathrm{K}$ & $\mathrm{O}$ & & $\mathrm{A} 4$ & $\mathrm{O}$ & $\mathrm{O}$ & $\mathrm{O}$ & $\dot{\mathrm{I}}$ \\
\hline & A5 & $\dot{\mathrm{I}}$ & $\mathrm{BK}$ & $\dot{\mathrm{I}}$ & $\mathrm{O}$ & & A5 & $\mathrm{O}$ & $\mathrm{O}$ & $\mathrm{BK}$ & $\mathrm{BK}$ \\
\hline & A6 & $\mathrm{BK}$ & $\dot{\mathrm{I}}$ & $\mathrm{BK}$ & $\mathrm{O}$ & & A6 & $\mathrm{O}$ & $\mathrm{BI}$ & $\mathrm{BI}$ & Bİ \\
\hline & A7 & $\mathrm{BK}$ & $\mathrm{O}$ & $\mathrm{O}$ & $\mathrm{BK}$ & & A7 & $\mathrm{O}$ & $\mathrm{O}$ & $\mathrm{BI}$ & $\dot{\mathrm{I}}$ \\
\hline \multirow{7}{*}{ K6 } & $\mathrm{A} 1$ & $\dot{\mathrm{I}}$ & Ç் & BÍ & $\dot{\mathrm{I}}$ & \multirow{7}{*}{ K13 } & A1 & $\dot{\mathrm{I}}$ & Ç் & $\mathrm{BI}$ & $\dot{\mathrm{I}}$ \\
\hline & A2 & $\mathrm{BK}$ & $\mathrm{K}$ & CK & $\mathrm{K}$ & & $\mathrm{A} 2$ & $\mathrm{O}$ & $\mathrm{BI}$ & $\mathrm{BI}$ & Bİ \\
\hline & $\mathrm{A} 3$ & $\mathrm{~K}$ & $\mathrm{~K}$ & $\mathrm{~K}$ & ÇK & & $\mathrm{A} 3$ & $\mathrm{O}$ & $\mathrm{BK}$ & $\mathrm{BI}$ & $\dot{\mathrm{I}}$ \\
\hline & $\mathrm{A} 4$ & ÇK & $\mathrm{O}$ & $\mathrm{K}$ & $\dot{\mathrm{I}}$ & & $\mathrm{A} 4$ & $\dot{\mathrm{I}}$ & $\mathrm{O}$ & $\dot{\mathrm{I}}$ & $\dot{\mathrm{I}}$ \\
\hline & A5 & $\mathrm{O}$ & $\mathrm{BI}$ & $\mathrm{O}$ & $\mathrm{O}$ & & A5 & $\mathrm{O}$ & BÍ & $\mathrm{O}$ & $\mathrm{O}$ \\
\hline & A6 & $\mathrm{K}$ & $\mathrm{K}$ & $\mathrm{BK}$ & $\mathrm{BK}$ & & A6 & Bİ & $\mathrm{O}$ & $\mathrm{BI}$ & Bİ \\
\hline & A7 & ÇK & BK & BK & $\mathrm{O}$ & & A7 & $\dot{\mathrm{I}}$ & $\dot{\mathrm{I}}$ & $\mathrm{O}$ & $\dot{\text { İ }}$ \\
\hline \multirow{7}{*}{ K7 } & A1 & $\dot{\mathrm{I}}$ & $\mathrm{BI}$ & Çİ & $\dot{\mathrm{I}}$ & & & & & & \\
\hline & A2 & $\mathrm{O}$ & Bİ & $\mathrm{O}$ & $\mathrm{O}$ & & & & & & \\
\hline & A3 & $\mathrm{O}$ & $\mathrm{O}$ & $\mathrm{O}$ & $\mathrm{O}$ & & & & & & \\
\hline & A4 & $\mathrm{O}$ & $\mathrm{O}$ & $\mathrm{O}$ & BI & & & & & & \\
\hline & A5 & BI & $\dot{\mathrm{I}}$ & BI & $\dot{\mathrm{I}}$ & & & & & & \\
\hline & A6 & $\mathrm{O}$ & $\mathrm{O}$ & $\mathrm{O}$ & $\mathrm{O}$ & & & & & & \\
\hline & A7 & $\mathrm{O}$ & BI & $\mathrm{O}$ & Bİ & & & & & & \\
\hline
\end{tabular}

Çizelge 9. Bulanık karar matrisi

\begin{tabular}{|c|c|c|c|c|c|c|c|}
\hline & \multicolumn{7}{|c|}{ Kriterler } \\
\hline 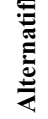 & K1 & K2 & $\mathbf{K} 3$ & K4 & K5 & K6 & K7 \\
\hline $\mathbf{A 1}$ & $(7,50,9,0,9,5)$ & $(6,75,8,13,9,0)$ & $(6,25,7,25,8,25)$ & $(6,75,8,13,9,0)$ & $(6,75,8,13,9,0)$ & $(6,75,8,13,9,0)$ & $(6,75,8,13,9,0)$ \\
\hline $\mathbf{A 2}$ & $(6,25,7,75,8,75)$ & $(4,50,5,75,7,0)$ & $(5,50,6,50,7,50)$ & $(5,25,6,50,7,75)$ & $(4,75,5,75,6,75)$ & $(1,0,1,88,3,25)$ & $(4,25,5,38,6,50)$ \\
\hline $\mathbf{A 3}$ & $(6,0,7,35,8,25)$ & $(5,75,6,88,8,0)$ & $(5,0,6,13,7,25)$ & $(5,50,6,50,7,50)$ & $(5,75,6,88,8,0)$ & $(0,75,1,50,2,75)$ & $(4,0,5,0,6,0)$ \\
\hline A4 & $(5,25,6,50,7,75)$ & $(4,50,6,13,7,25)$ & $(6,0,7,25,8,50)$ & $(4,75,6,13,7,50)$ & $(2,50,3,50,4,50)$ & $(3,0,3,75,5,0)$ & $(4,25,5,38,6,50)$ \\
\hline A5 & $(6,0,7,38,8,25)$ & $(4,50,5,75,7,0)$ & $(5,0,6,13,7,25)$ & $(4,50,5,75,7,0)$ & $(5,0,6,13,7,25)$ & $(4,25,5,38,6,50)$ & $(6,0,7,25,8,50)$ \\
\hline A6 & $(7,50,9,0,9,5)$ & $(5,0,6,50,8,0)$ & $(6,50,7,63,8,75)$ & $(6,50,7,75,8,50)$ & $(3,75,5,0,6,25)$ & $(1,50,2,75,4,0)$ & $(4,0,5,0,6,0)$ \\
\hline A7 & $(6,0,7,38,8,25)$ & $(4,75,6,13,7,5)$ & $(5,75,6,88,8,0)$ & $(4,0,5,0,6,0)$ & $(3,0,4,25,5,50)$ & $(2,0,3,0,4,50)$ & $(4,50,5,75,7,0)$ \\
\hline 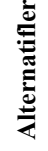 & K8 & K9 & K10 & K11 & K12 & K13 & \\
\hline A1 & $(6,50,7,63,8,75)$ & $(6,25,7,75,8,75)$ & $(6,75,8,13,9,0)$ & $(6,25,7,75,8,75)$ & $(6,0,7,38,8,25)$ & $(6,75,8,13,9,0)$ & \\
\hline A2 & $(4,50,5,75,7,0)$ & $(4,25,5,38,6,50)$ & $(3,0,4,25,5,50)$ & $(5,50,6,88,8,25)$ & $(2,0,3,50,5,0)$ & $(4,75,6,13,7,50)$ & \\
\hline A3 & $(4,50,5,75,7,0)$ & $(4,25,5,38,6,50)$ & $(4,25,5,38,7,0)$ & $(3,75,5,0,6,25)$ & $(5,50,6,50,7,50)$ & $(4,50,5,75,7,0)$ & \\
\hline A4 & $(6,0,7,25,8,50)$ & $(5,0,6,50,8,0)$ & $(4,50,5,75,7,0)$ & $(4,75,5,75,6,75)$ & $(4,75,5,75,6,75)$ & $(6,25,7,25,8,25)$ & \\
\hline A5 & $(3,50,4,63,5,75)$ & $(4,25,5,38,6,50)$ & $(2,0,3,0,4,50)$ & $(5,0,5,38,6,50)$ & $(3,0,4,25,5,50)$ & $(4,25,5,38,6,50)$ & \\
\hline A6 & $(4,50,5,75,7,0)$ & $(5,25,6,50,7,75)$ & $(4,75,5,75,6,75)$ & $(5,50,6,50,7,50)$ & $(4,75,6,13,7,50)$ & $(4,75,6,13,7,50)$ & \\
\hline A7 & $(3,75,5,0,6,25)$ & $(3,50,4,63,5,75)$ & $(3,50,4,63,5,75)$ & $(4,0,5,0,6,0)$ & $(5,0,6,13,7,25)$ & $(6,25,7,25,8,25)$ & \\
\hline
\end{tabular}


Çizelge 10. Normalize edilmiş bulanık karar matrisi

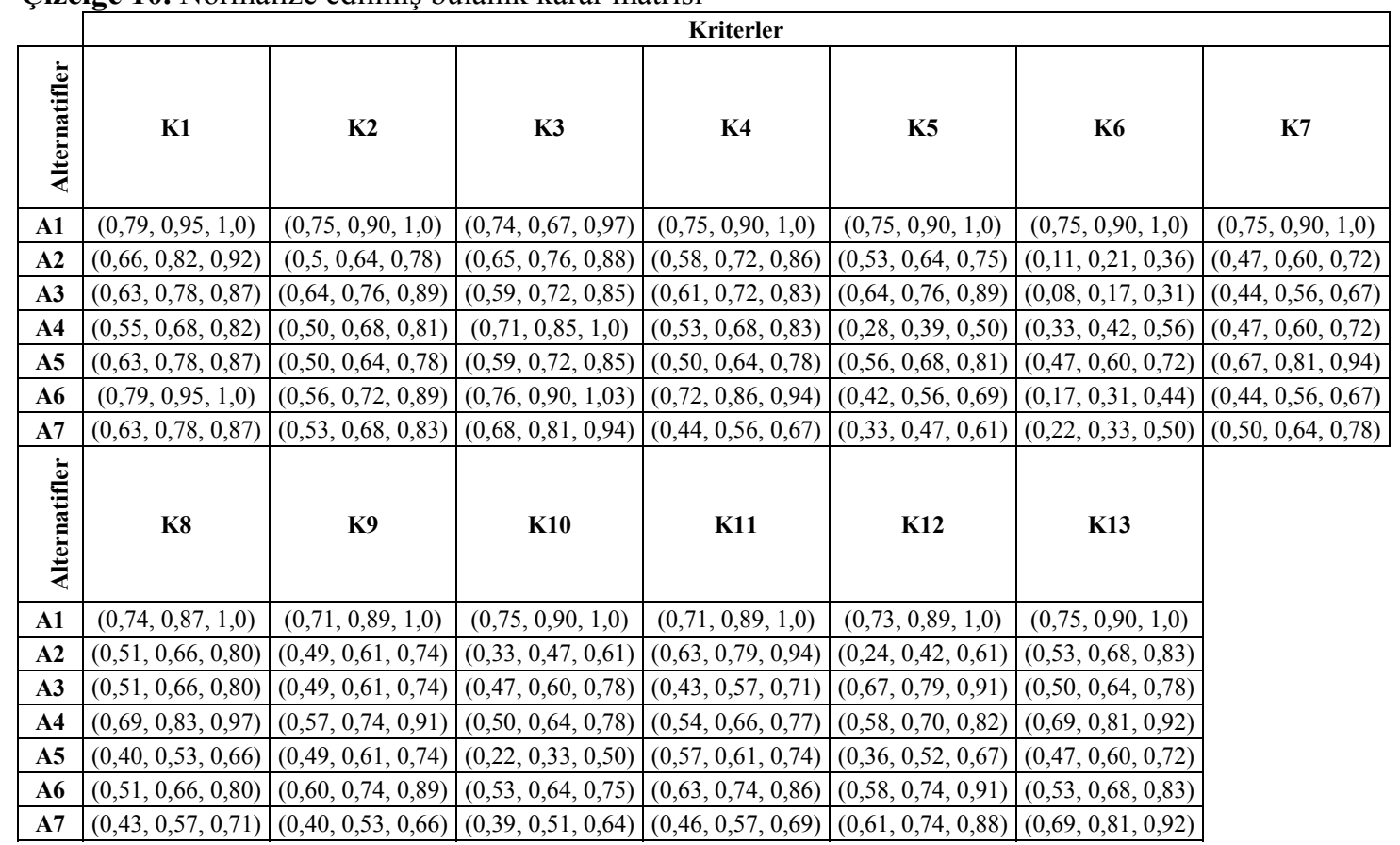

Çizelge 11. Ağırlıklı normalize edilmiş bulanık karar matrisi

\begin{tabular}{|c|c|c|c|c|c|c|c|}
\hline & \multicolumn{7}{|c|}{ Kriterler } \\
\hline 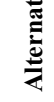 & K1 & K2 & K3 & K4 & K5 & K6 & K7 \\
\hline A1 & $(0,59,0,85,0,95)$ & $(0,45,0,65,0,85)$ & $(0,42,0,47,0,75)$ & $(0,49,0,7,0,85)$ & $(0,17,0,32,0,48)$ & $(0,06,0,12,0,3)$ & $(0,38,0,55,0,73)$ \\
\hline A2 & $(0,49,0,73,0,88)$ & $(0,3,0,46,0,66)$ & $(0,37,0,54,0,68)$ & $(0,38,0,56,0,73)$ & $(0,12,0,22,0,36)$ & $(0,01,0,03,0,11)$ & $(0,24,0,37,0,52)$ \\
\hline $\mathbf{A 3}$ & $(0,47,0,7,0,83)$ & $(0,38,0,55,0,76)$ & $(0,34,0,5,0,66)$ & $(0,4,0,56,0,71)$ & $(0,14,0,27,0,42)$ & $(0,01,0,02,0,09)$ & $(0,22,0,34,0,48)$ \\
\hline A4 & $(0,41,0,62,0,78)$ & $(0,3,0,49,0,68)$ & $(0,41,0,6,0,78)$ & $(0,34,0,53,0,71)$ & $(0,06,0,14,0,24)$ & $(0,03,0,06,0,17)$ & $(0,24,0,37,0,52)$ \\
\hline A5 & $(0,47,0,7,0,83)$ & $(0,3,0,46,0,66)$ & $(0,34,0,5,0,66)$ & $(0,33,0,5,0,66)$ & $(0,13,0,24,0,38)$ & $(0,04,0,08,0,22)$ & $(0,33,0,49,0,68)$ \\
\hline A6 & $(0,59,0,85,0,95)$ & $(0,33,0,52,0,76)$ & $(0,44,0,63,0,8)$ & $(0,47,0,67,0,8)$ & $(0,09,0,19,0,33)$ & $(0,01,0,04,0,13)$ & $(0,22,0,34,0,48)$ \\
\hline A7 & $(0,47,0,7,0,83)$ & $(0,32,0,49,0,71)$ & $(0,39,0,57,0,73)$ & $(0,29,0,43,0,57)$ & $(0,08,0,17,0,29)$ & $(0,02,0,05,0,15)$ & $(0,25,0,39,0,56)$ \\
\hline 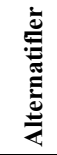 & K8 & K9 & K10 & K11 & K12 & K13 & \\
\hline A1 & $(0,26,0,4,0,58)$ & $(0,36,0,54,0,68)$ & $(0,15,0,28,0,43)$ & $(0,3,0,48,0,65)$ & $(0,20,0,35,0,50)$ & $(0,21,0,35,0,50)$ & \\
\hline A2 & $(0,18,0,3,0,46)$ & $(0,24,0,38,0,5)$ & $(0,07,0,15,0,26)$ & $(0,27,0,42,0,61)$ & $(0,07,0,16,0,30)$ & $(0,15,0,26,0,42)$ & \\
\hline $\mathbf{A 3}$ & $(0,18,0,3,0,46)$ & $(0,24,0,38,0,5)$ & $(0,09,0,19,0,33)$ & $(0,18,0,31,0,46)$ & $(0,18,0,31,0,45)$ & $(0,14,0,25,0,39)$ & \\
\hline A4 & $(0,24,0,38,0,56)$ & $(0,29,0,46,0,62)$ & $(0,1,0,2,0,33)$ & $(0,23,0,35,0,5)$ & $(0,16,0,27,0,41)$ & $(0,19,0,31,0,46)$ & \\
\hline A5 & $(0,14,0,24,0,38)$ & $(0,24,0,38,0,5)$ & $(0,04,0,1,0,21)$ & $(0,24,0,33,0,48)$ & $(0,10,0,20,0,33)$ & $(0,13,0,23,0,36)$ & \\
\hline A6 & $(0,18,0,3,0,46)$ & $(0,3,0,46,0,6)$ & $(0,11,0,2,0,32)$ & $(0,27,0,4,0,56)$ & $(0,16,0,29,0,45)$ & $(0,15,0,26,0,42)$ & \\
\hline A7 & $(0,15,0,26,0,41)$ & $(0,2,0,32,0,44)$ & $(0,08,0,16,0,27)$ & $(0,19,0,31,0,45)$ & $(0,17,0,29,0,44)$ & $(0,19,0,31,0,46)$ & \\
\hline
\end{tabular}


Uzaklıkların belirlenmesinden sonra, (18) eşitliği ile her bir alternatifin yakınlık katsayısı hesaplanır. Her alternatif için $d_{i}{ }^{*}, d_{i}{ }^{-}$ve $C_{i}$ değerleri Çizelge 12'de verilmiştir.

Çizelge 12. FPIS ve FNIS'den uzaklıklar ve yakınlık katsayı değerleri

\begin{tabular}{|c|c|c|c|c|}
\hline Alternatifler & $d_{i}{ }^{*}$ & $d_{i}{ }^{-}$ & $d_{i}{ }^{*}+d_{i}{ }^{-}$ & $\mathrm{C}_{i}$ \\
\hline A1 & 7,16 & 6,37 & 13,52 & 0,471 \\
\hline A2 & 8,52 & 4,90 & 13,42 & 0,365 \\
\hline A3 & 8,42 & 4,97 & 13,40 & 0,371 \\
\hline A4 & 8,34 & 5,09 & 13,43 & 0,379 \\
\hline A5 & 8,60 & 4,79 & 13,40 & 0,358 \\
\hline A6 & 8,03 & 5,42 & 13,45 & 0,403 \\
\hline A7 & 8,64 & 4,75 & 13,39 & 0,355 \\
\hline
\end{tabular}

$\mathrm{C}_{\mathrm{i}}$ değeri en yüksek olan alternatif, en uygun ventilatör olacaktır. Çizelge 12'ye göre alternatifleri siralayacak olursak şu siralama elde edilir: A1 > A6 $>$ A4 $>$ A3 $>$ A2 $>$ A5 $>$ A7. Yani, ventilatör seçimi için en uygun aday Drager'dir ve bunu sırasıyla Ertunç-Ertan, Hamilton, Sum-1, Maque, GE ve Servo takip etmektedir.

\section{SONUÇLAR}

Yoğun bakım ünitelerinde yatan hastalar için ventilatör cihazı hayati öneme sahiptir. Bu önemli cihazın yanlış seçimi veya parametrelerinin uygun ayarlanmaması hastaların tedavisinde geri dönülemez sonuçlara neden olabilir. Literatür incelendiğinde, sadece bir çalışmanın [9] ventilatör seçimine odaklandığı gözlemlenmiştir. $\mathrm{Bu}$ çalışmada da ventilatör seçimi için sadece AHP yöntemine başvurulmuştur. Literatürdeki bu boşluğu doldurma amacı ile bu çalışmada, ventilatör seçimi için AHP ve bulanık TOPSIS yöntemleri olmak üzere iki tane ÇKKV yöntemine başvurulmuştur. Yapılan uygulama neticesinde iki yöntemin de ventilatörlerin seçimi için aynı sıralamayı verdiği ve en iyi alternatif olarak Drager'i önerdiği gözlenmiştir.

Gelecek çalışmalarda, konu, başka ÇKKV yöntemleri ile çözülebilir, uygulama alanı genişletilebilir, kriter ağırlıkları ve değerlendirmeler değiștiğinde sonuca etkisini gözlemlemek için duyarlılık analizleri yapılabilir.

\section{KAYNAKLAR}

1. Torpy, J.M., Campbell, A.D., Glass, R.M., 2010. Mechanical Ventilation, Journal of American Medical Association, 902.

2. Kacmarek, R.M., 2011. The Mechanical Ventilator: Past, Present, and Future, Respiratory Care, 1170-1180.

3. Perel, A, Stock, M.C., 1992. Handbook of Mechanical Ventilatory Support (First Edition), Williams and Wilkins, Philadelphia, 7.

4. Kacmarek, R.M., Venegas, J., 1987. Mechanical Ventilatory Rates and Tidal Volumes. Respiratory Care, 32, 466.

5. Abou-Shala, N., Meduri, U., 1996. Noninvasive Mechanical Ventilation in Patients with Acute Respiratory Failure, Critical Care Medicine, 24, 705-715.

6. Mehta, S., Hill N.S., 2001. Noninvasive Ventilation. American Journal of Respiratory Critical Care Medicine, 163, 540-577.

7. Nava, S., Hill, N., 2013. Non-Invasive Ventilation in Acute Respiratory Failure, Lancet, 374, 250-259.

8. Brochard, L., 2003. Mechanical Ventilation: Invasive Versus Noninvasive, European Respiratory Journal, 47, 31-37.

9. Sloane, E.B., Liberatore, M. J., Nydick, R.L., Luo, W., Chung, Q.B., 2003. Using the Analytic Hierarchy Process as a Clinical Engineering Tool to Facilitate an Iterative, Multidisciplinary, Microeconomic Health Technology Assessment, Computers \& Operations Research, 30(10), 1447-1465.

10. Diaby, V., Campbell, K., Goeree, R., 2013. Multi-Criteria Decision Analysis (MCDA) in Health Care: A Bibliometric Analysis, Operations Research for Health Care, 2(1-2), 20-24.

11. Karacan, I., Tozan, H., Karatas, M., 2016. Multi-Criteria Decision Methods in Helath Technology Assessment: A Brief Literature Review, Eurasian Journal of Health Technology Assessment, 1(1), 12-19.

12. Liberatore, M.J., Nydick, R.L., 2008. The Analytic Hierarchy Process in Medical and 
Health Care Decision Making: A Literature Review, European Journal of Operations Research, 189(1), 194-207.

13. Schmidt, K., Aumann, I., Hollander, I., Damm, K., von der Schulenburg, J.M.G., 2015. Applying the Analytic Hierarchy Process in Healthcare Research: A Systematic Literature Review and Evaluation of Reporting, BMC Medical Informatics and Decision Making, 15(112), 27.

14. Dolan, J.G., Isseslhardt, B.J., Cappuccio, J.D., 1989. The Analytic Hierarchy Process in Medical Decision Making: A Tutorial, 9(1), 40-50.

15. Suner, A., Celikoglu, C.C., Dicle, O., Sokmen, S., 2012. Sequential Decision Tree Using the Analytical Hierarchy Process for Decision Support in Rectal Cancer, Artificial Intelligence in Medicine, 56(1), 59-68.

16. Aktas, A., Cebi, S., Temiz, I., 2015. A New Evaluation Model for Service Quality of Health Care Systems Based on AHP and Information Axiom, Journal of Intelligent \& Fuzzy Systems, 28(3), 1009-1021.

17. Liu, H.C., Wu, J., Li, P., 2013. Assessment of Health-Care Waste Disposal Methods Using a VIKOR-Based Fuzzy Multi-Criteria Decision Making Method, 33(12), 2744-2751.

18. Chang, T.H., 2014. Fuzzy VIKOR Method: A Case Study of the Hospital Service Evaluation in Taiwan, Information Sciences, 271, 196-212.

19. Afful-Dadzie, E., Nabareseh, S., Oplatkova, Z.K., Klimek, P., 2016. Model for Assessing Quality of Online Health Information: A Fuzzy VIKOR Based Method, Journal of MultiCriteria Decision Analysis, 23(1-2), 49-62.

20. Nilashi, M, Ahmadi, H., Ahani, A., Ravangard, R., Bin Inrahim, O., 2016. Determining the Importance of Hospital Information System Adoption Factors Using Fuzzy Analytic Network Process (ANP), Technological Forecasting \& Social Change, 111, 244-264.

21. Chou, S.Y., Yu, V.F., Dewabharata, A., Dat, L.Q., 2012. A Fuzzy TOPSIS Approach for Medical Provider Selection and Evaluation, Proceedings of 2012 International Conference on Fuzzy Theory and Its Applications, 16-18,
National Chung Hsing University, Taichung, Taiwan.

22. Lu, M.T., Lin, S.W., Tzeng, G.H., 2013. Improving RFID Adoption in Taiwan's Healthcare Industry Based on DEMATEL Technique with a Hybrid MCDM Model, Decision Support Systems, 56, 259-269.

23. Liou, J.J.H., Lu, M.T., Hu, S.K., Cheng, C.H., Chuang, Y.C., 2017. A Hybrid MCDM Model for Improving the Electronic Health Record to Better Serve Client Needs, Sustainability, 9(10), 1-13.

24. Kulak, O., Goren, H.G., Supciller, A.A., 2015. A New Multi Criteria Decision Making Approach for Medical Imaging Systems Considering Risk Factors, Applied Soft Computing, 35, 931-941.

25. Akdag, H., Kalaycı, T., Karagoz, S., Zulfikar, H., Giz, D., 2014. The Evaluation of Hospital Service Quality by Fuzzy MCDM, Applied Soft Computing, 23, 239-248.

26. Vachova, L., Hajdikova, T., 2017. Evaluation of Czech Hospitals Performance Using MCDM Methods, Proceedings of the World Congress on Engineering and Computer Science 2017, 14, San Francisco, USA.

27. Buyukozkan, G., Ciftci, G., 2012. A Combined Fuzzy AHP and Fuzzy TOPSIS Based Strategic Analysis of Electronic Service Quality in Healthcare Industry, Expert Systems with Applications, 39(3), 2341-2354.

28. Evaluating Health-Care Waste Treatment Technologies Using a Hybrid Multi-Criteria Decision Making Model, Renewable and Sustainable Energy Reviews, 41, 932-942.

29. Lu, C., You, J.X., Liu, H.C., Li, P., 2016. Health-Care Waste Treatment Technology Selection Using the Interval 2-Tuple Induced TOPSIS Method, International Journal of Environmental Research and Public Health, 13(6), 1-16.

30. Tanino, T., Tanaka, T., Inuiguchi, M., 2003. Multi-Objective Programming and Goal Programming Theory and Applications, First Edition, Springer-Verlag Berlin Heidelberg.

31. Saaty, T.L., 1994. How to Make a Decision: The Analytic Hierarchy Process, Interface, 19-43. 
32. Vargas, L.G., 1990. An Overview of the Analytic Hierarchy Process and its Applications, European Journal of Operational Research, 48(1), 2-8.

33. Hwang, C.L., Yoon, K., 1981. Multiple Attributes Decision Making Methods and Applications, Springer, Berlin Heidelberg.

34. Zadeh, L.A., 1965. Fuzzy Sets, Information and Control, 8, 338-353.

35. Chen, C.T., 2000. Extensions of the TOPSIS for Group Decision Making Under Fuzzy Environment, Fuzzy Sets and Systems, 114, $1-9$.

36. Chen, C.T., Lin, C.T., Huang, S.F., 2006. A Fuzzy Approach for Supplier Evaluation and Selection in Supply Chain Management, International Journal of Production Economics, 102(2), 289-301. 